\title{
TESTING OF INITIATION OF ROTATING DETONATION PROCESS IN HYDROGEN-AIR MIXTURES
}

\author{
Włodzimierz Balicki, Andrzej Irzycki, Borys Lukasik, Krzysztof Snopkiewicz \\ Institute of Aviation, Propulsion Department \\ Krakowska Av. 110/114, 02-256 Warszawa \\ tel.: +48228460011 ext. 337, fax: +488465774 \\ e-mail: balicki@ilot.edu.pl
}

\begin{abstract}
The paper presents results of some research work done in the project, which aims to apply of an innovative combustion chamber to the turbine engine. Expected benefits of using of a new chamber in which classical deflagration type combustion process would be replaced with a detonation combustion type, arise from greater efficiency of FickettJacobs cycle, which corresponds to rotating detonation combustion, in comparison to "classical" Brayton cycle, characteristic of deflagration combustion.

The presented task concerned fundamental research carried out on test bench designed and built at the Institute of Aviation in Warsaw. To initiate the detonation combustion in the fuel-air mixtures the ignition device of appropriately high energy is necessary. The released energy should be directed to the area where the mixture has proper constitution - preferably close to stoichiometric one.

Four different ignition manners were examined in the course of research: electrical ignition system adapted from turbine engine (semiconductor spark plug), powder charge ignition (handgun cartridges), detonation primer ignition using pentryt, and high voltage discharge (plasma jet). The appearance of detonation type combustion was identified on the basis of combustion gas pressure run, measured using piezoelectric sensors at a frequency of $1 \mathrm{MHz}$.
\end{abstract}

Keywords: internal combustion engine, turbine engines, combustion chamber, rotating detonation

\section{Introduction}

Aircraft turbine engines are a kind of "transducers", in which the chemical energy contained in fuel is converted into thrust. This "treatment" is bound to incurring engine's manufacturing and operating cost (including fuel costs, repairs), and the costs of charging of the environment in which we live with noise and toxic exhaust gas components. Current trends in development of these engines are driving towards increasing of service life (e.g. one of CF6-80C2 aircraft motors operated on the Boeing 767 at LOT attained overhauling period of 27,000 hours) as well as reducing fuel consumption through increase efficiency and reduction of nitrogen oxides and unburned hydrocarbons and soot content in the exhaust. The chance of realizing of above-mentioned goals gives modification of combustion process which proceeds in engine's combustion chambers, namely replacement of classical combustion with detonative-deflagration type combustion (see Tab. 1).

Tab. 1. Differences between deflagration and detonation processes [5, 6]

\begin{tabular}{|c|c|c|}
\hline Feature & Deflagration & Detonation \\
\hline Flame front velocity & $\begin{array}{l}\text { Combustion velocity of the order of } \\
\text { dozen } \mathrm{m} / \mathrm{s}\end{array}$ & Detonation velocity of the order of $\mathrm{km} / \mathrm{s}$ \\
\hline Dimensions of combustion chamber & Large combustion chamber & Short combustion zone \\
\hline Composition of fuel mixture & Combustion at stoichiometric ratio & Combustion (detonation) of lean mixture \\
\hline Exhaust gas temperature & Very high temperature & Lower temperature \\
\hline Emission of nitrogen oxides & High emission of NOx & Low NOx emission \\
\hline $\begin{array}{l}\text { Need for cooling exhaust gas at the } \\
\text { outlet from the chamber }\end{array}$ & $\begin{array}{l}\text { Necessity to mix extra air before } \\
\text { turbine }\end{array}$ & No necessity to mix extra air \\
\hline Change of gas pressure in the chamber & Pressure drop due to combustion & Pressure increase due to detonation \\
\hline Construction simple / complex & & More simple design \\
\hline
\end{tabular}




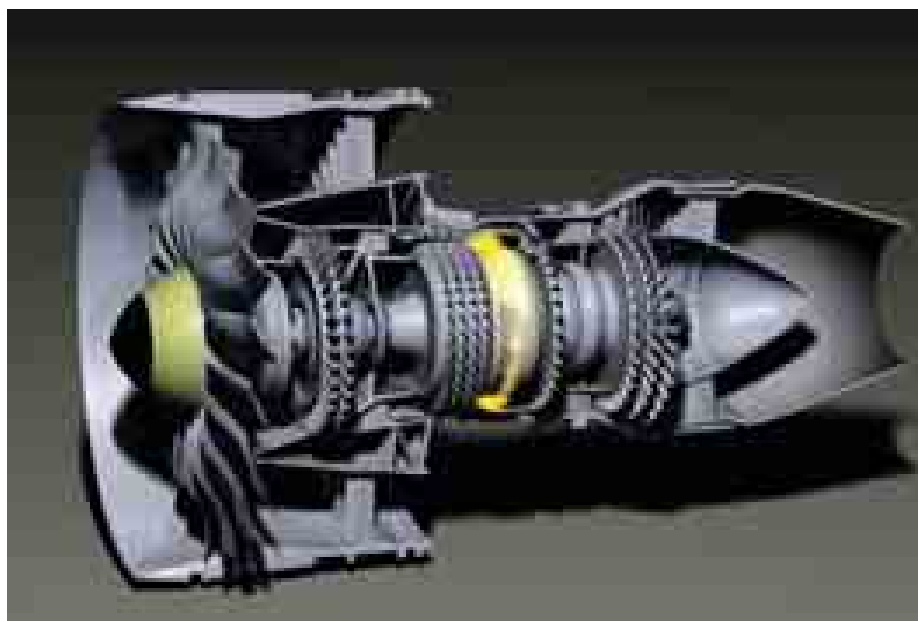

Fig. 1. Idea of a turbine engine, in which classical, deflagration combustion chamber has been, replaced with a shorter, rotating detonation ( $R D E$ ) type, combustion chamber

\section{Composition of mixture and minimum energy of ignition system}

Initiation of detonation in a combustible mixture is much more difficult than the start of deflagration combustion. It depends on various factors: initial energy of the starter, geometry of the combustion chamber, type of components, which form combustible mixture, and of its composition. The subject of research works presented here was the influence of the air-hydrogen mixture to the possibility of detonation initiation using different kind of starting devices.

Similar tests are conducted at various research centres from about 20 years. Characteristics of ignitability of hydrogen - oxygen and hydrogen - air mixtures were determined during implementation of the EU Project SAFEKINEX (budget $€ 3.5$ million) [9]. Mixtures of other gases were studied as well (see Tab. 2). In Poland, such research was conducted at the Institute of Heat Engineering at Warsaw University of Technology [4]. Fig. 2 presents diagram of one the stands applied at IHE WUT.

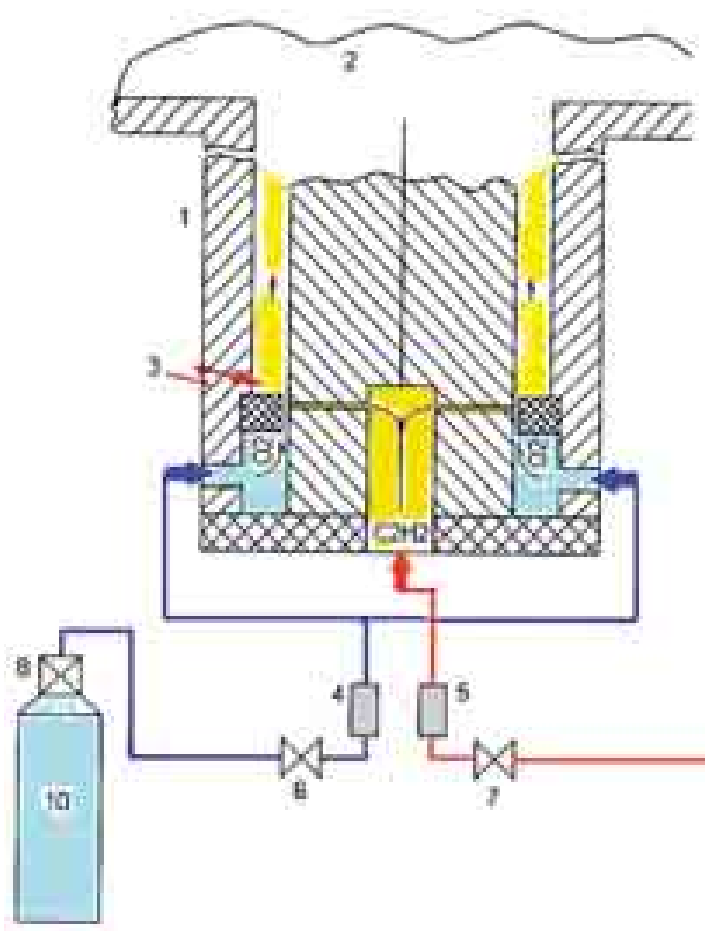

Fig. 2. Diagram of test stand applied at IHE WUT: 1 - Detonation chamber; 2 - outlet to pressure tank; 3 - starting system; 4, 5 - anti-flame fuses; 6, 7 - solenoid valves; 8 - ball valve; 10 -oxygen bottle (based on [4]) 
Tab. 2. Experimental determined limits of gas mixture composition which undergo detonation or deflagration combustion (based on [1])

\begin{tabular}{|l|c|c|c|c|}
\hline \multirow{2}{*}{ Kind of mixture } & \multicolumn{2}{|c|}{ Lean limit [\%vol.] } & \multicolumn{2}{c|}{ Reach limit [\%vol.] } \\
\cline { 2 - 5 } & Deflagration & Detonation & Deflagration & Detonation \\
\hline Hydrogen - oxygen & 4.6 & 15.0 & 90 & 93.9 \\
\hline Hydrogen - air & 4.0 & 18.3 & 59 & 74.0 \\
\hline Hydrogen + CO - air & 12.5 & 17.2 & 91 & 92.0 \\
\hline Ammonia - oxygen & 13.5 & 25.4 & 75 & 79 \\
\hline Propane - oxygen & 2.4 & 3.2 & 37 & 55 \\
\hline Acetylene - oxygen & 2.8 & 3.5 & 92 & 93 \\
\hline Butane - air & 1.85 & 2.8 & 4.5 & 30.5 \\
\hline
\end{tabular}

Another important parameter is the minimum (critical) energy of detonation initiation. It was found that it depends on the detonation cell width and pressure of the mixture. In study [7], the following model of calculation was presented:

$$
E_{o}=k_{j} \cdot \rho_{o} \cdot I \cdot V_{D E T}^{j+3} \cdot\left[\frac{j+3}{2}\right]^{(j+1)} \cdot \tau^{(j+1)},
$$

where:

$\tau=\frac{2 \cdot h_{K}}{V_{D E T}}$

$\mathrm{I}=0.626$ for the adiabatic exponent $\mathrm{k}=1.4$ and a cylindrical detonation,

$h_{K}-$ detonation cell width,

$V_{D E T}$ - detonation wave velocity,

$\rho_{o} \quad-$ density of gas mixture,

the $\boldsymbol{k}_{\boldsymbol{j}} \mathrm{i} \boldsymbol{j}$ values depend on the form of detonation and adopt values as in the following table:

Tab. 3 Forms of detonation

\begin{tabular}{|l|c|c|}
\hline Form of detonation & $k j$ & $j$ \\
\hline Plane & 1 & 0 \\
\hline Cylindrical & $2 \pi$ & 1 \\
\hline Spherical & $4 \pi$ & 2 \\
\hline
\end{tabular}

\section{Diagram of test stand}

Structural diagram of test stand used for initial studies of detonative combustion phenomenon in Institute of Aviation is shown in Fig. 3

On this test stand a phenomenon of hydrogen-air mixtures detonation has been studied. Hydrogen was derived from set of four pressure cylinders connected in parallel as common feeding bus and the air - from $1.3 \mathrm{~m}^{3}$ tank supplied by highly efficient piston compressor.

An important matter was the appropriate location of detonator - in place where the streams of hydrogen and air are mixed properly. The distance from outlet of the injector to detonator was calculated on the basis of numerical simulations of mixing of two gases at different pressures in the feeding collectors (see Fig. 4). 


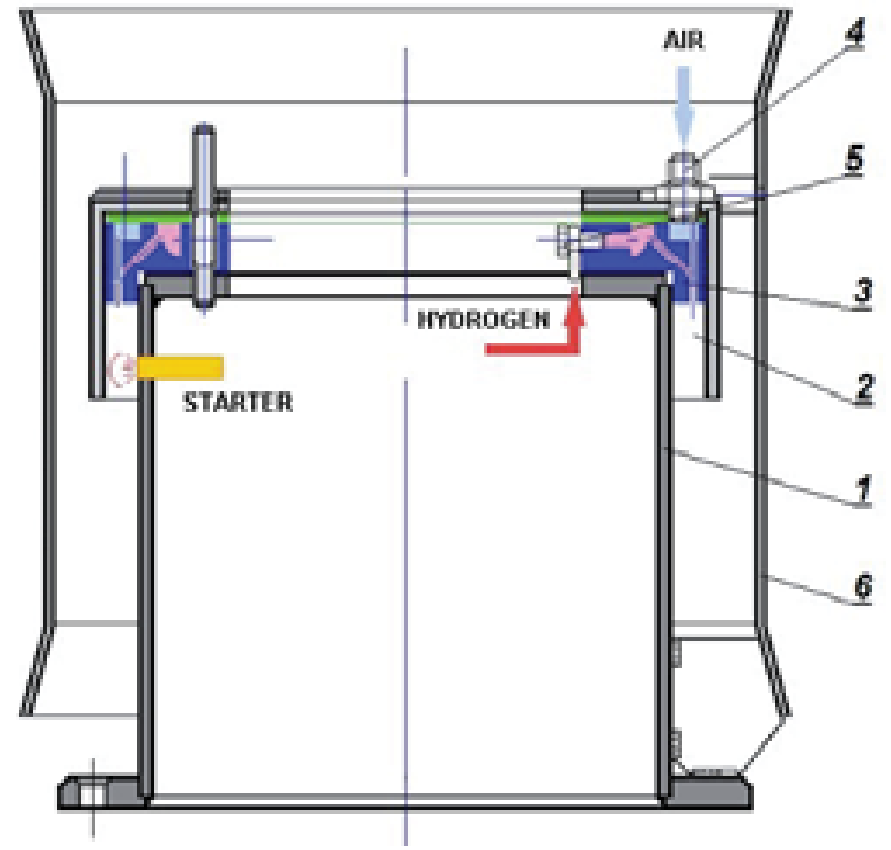

Fig. 3. Schematic diagram of test stand at Institute of Aviation: 1 - Basis; 2 - detonative combustion chamber; 3 - ring of injectors; 4 - air supply connector; 5 - hydrogen supply connector; 6 - outside housing

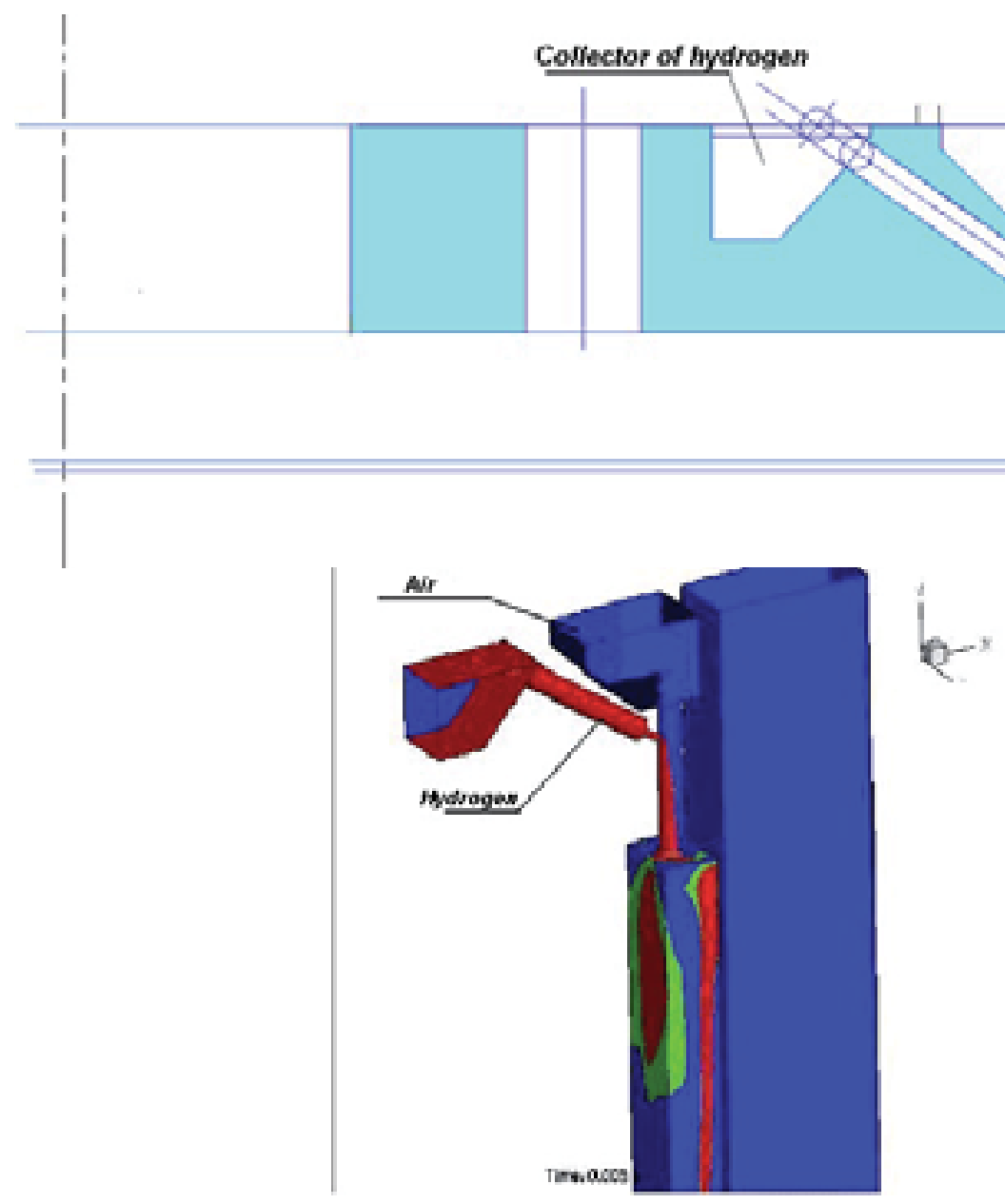

Fig 4. Schematic diagram of ring of injectors and results of mixing of air and hydrogen streams calculations executed using the software REFLOPS2 (Reactive Euler Flow Solver for Propulsion Systems) on the assumption that the pressure of both agents in intake manifolds are equal and amount to 6 bars (red colour denotes excess of hydrogen, green colour - the stoichiometric composition) 
Flow of mixture was opened and closed using solenoid controlled by logic signals derived from measuring and controlling unit. The same unit served a generation of firing signal to detonator (see Fig. 5).

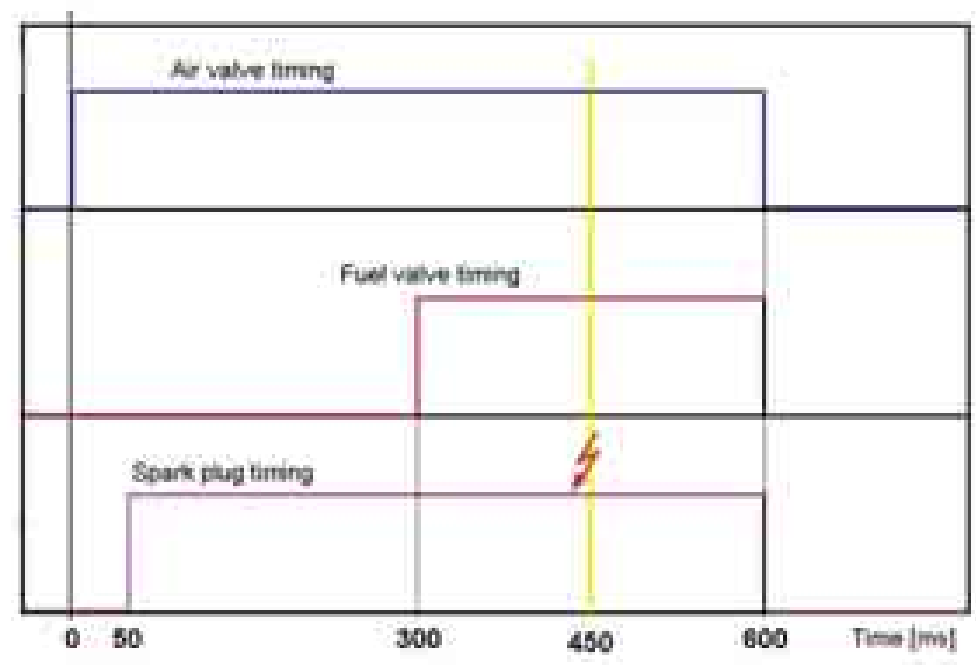

Fig. 5. Timing example of control gates that generate opening and closing signals to solenoid valves and firing signal to detonator

\section{Description of systems used to initiate a detonation in a hydrogen and air mixture}

\subsection{Ignition system adapted from turbine engine}

In this case solid-state spark plug SW-15 and voltage converter $28 \mathrm{~V} / 2000 \mathrm{~V}$ was applied, previously used to start turbine engine K-15.

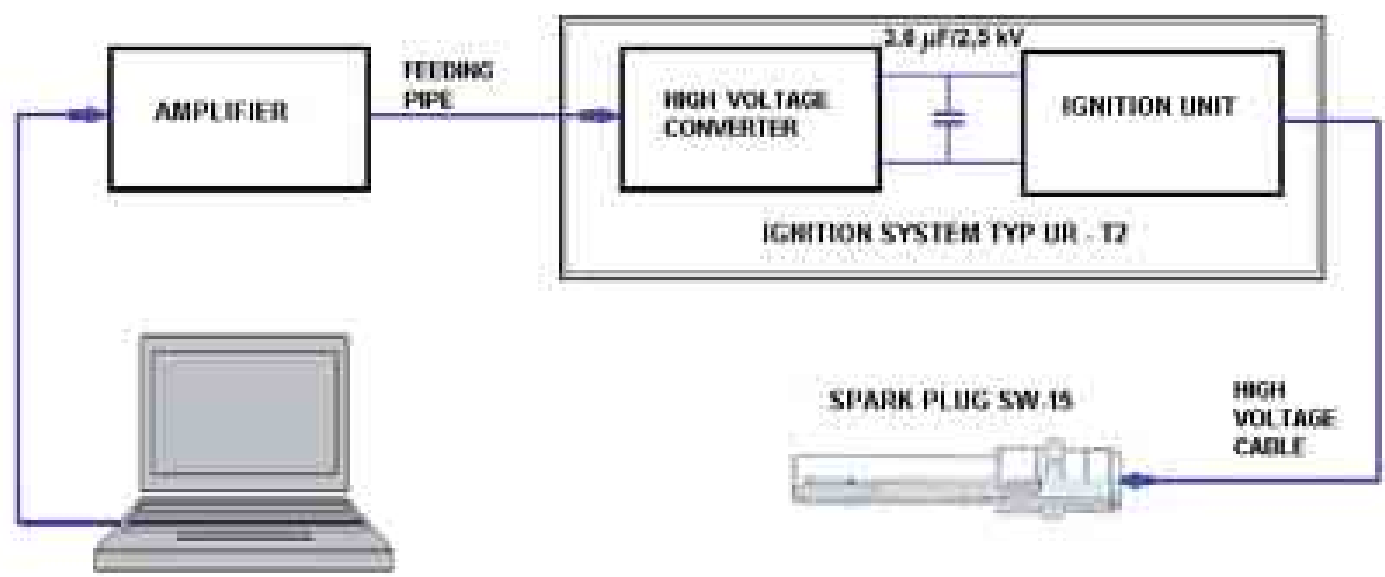

Fig. 6. Schematic diagram of the ignition system from turbine engine

Principle of operation: After sending signal from computer to the amplifier a voltage of $24 \mathrm{~V}$ is applied to ignition system (UR-T2). High voltage converter charges a capacitor $3.6 \mathrm{mF} / 2.5 \mathrm{kV}$. When crossing the threshold voltage (approximately $2000 \mathrm{~V}$ ) the capacitor is discharged at the spark plug causing flashover. With supply voltage of about $24 \mathrm{~V}$ the above-described process is repeated about 3 times per second. Knowing, from tests carried out before, the delay between feeding of amplifier and the moment of flashover, you can choose time sequence of enabling and disabling power amplifier in such way, which enables obtaining only one discharge of capacitor on spark plug during ongoing test. 
Estimation of shock energy (for a capacitor with a capacity of $3.6 \mathrm{mF}$ and voltage drop of $1000 \mathrm{~V}$ ):

$$
\mathrm{E}=\mathrm{C}^{*} \Delta \mathrm{U}^{2}=3.6 * 10^{-6} *(1000)^{2}=3.6 * 1=3.6[\mathrm{~J}] \text {. }
$$

From the theoretical energy the losses in ignition system, high voltage cable, and spark plug should be subtracted. Assuming total energy loss at about $40 \%$, the discharge energy will decrease to about $2[\mathrm{~J}]$.

Test of firing frequency: Depending on supply voltage feeding the ignition system UR-T2 the speed of capacitor charging will change. Spark-over starts when voltage on capacitor plates reaches $2000 \mathrm{~V}$. The results of flashover testing are presented in Tab. 4.

Tab. 4. Frequency - supply voltage relation for flashovers of spark plug SW-15 fed by ignition system UR-T2

\begin{tabular}{|c|c|c|c|c|c|c|}
\hline $\mathbf{U}_{\text {SUPPL }}$ & {$[V]$} & 15 & 18 & 20 & 25 & 27 \\
\hline $\mathbf{f}$ & {$[1 / \mathrm{s}]$} & 1.8 & 2.2 & 2.6 & 3.4 & 3.8 \\
\hline
\end{tabular}

\subsection{Utilization of blank pistol cartridges}

Principle of operation: Firing mechanism (,gun”) with firing lock servo-operated by computer has been loaded with 0.22 " blank cartridges (manufacturer: German company "Umarex"). Each cartridge contains $0.16 \mathrm{~g}$ of black powder. After inserting the cartridge into the chamber, breechblick with striker are stretched and blocked by trigger mechanism, which is operated using servomechanism. When computer sends a "Start" signal, the lever of servomechanism pulls the trigger mechanism, releases firing lock with the striker, which moves under the force of stretched spring and hit against cartridge primer causing firing and ejection of powder gases into the test chamber.

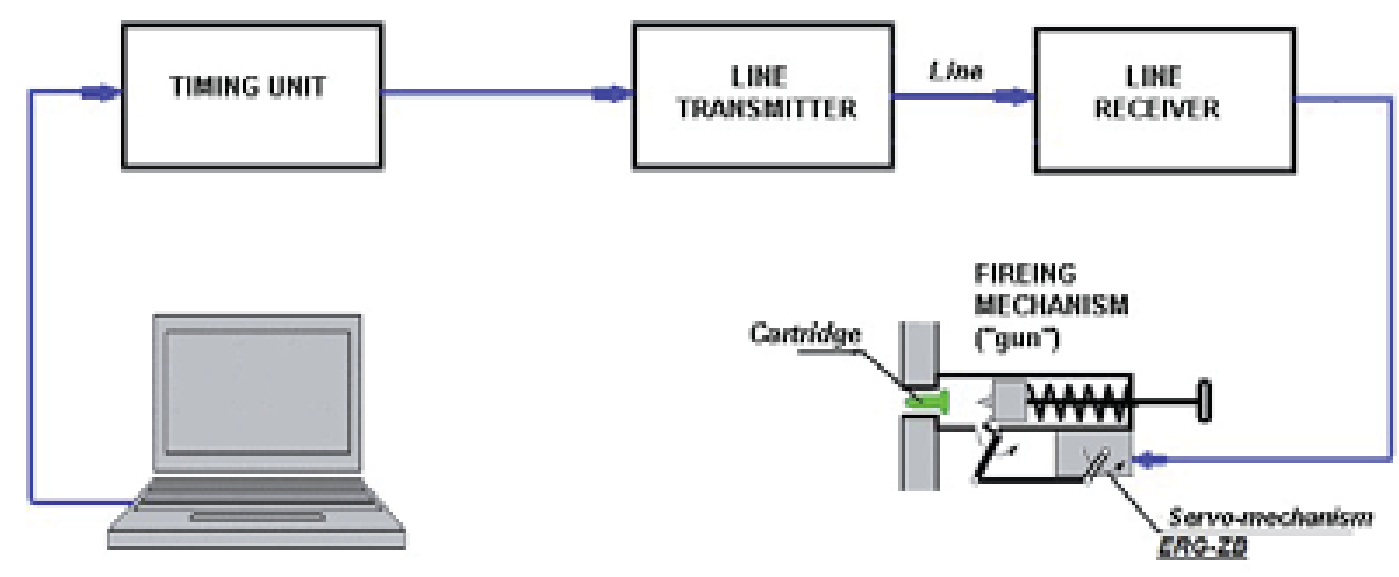

Fig. 7. Schematic diagram of system controlling of firing mechanism

An attempt was made to initiate a cartridge using the electric current of about $100 \mathrm{~A}$, which had been applied to cartridge primer (from 12V/55 Ah starter battery).

Estimating energy of powder gases

The properties of black powder are as follows:

- The energy of explosion: $2.8 \mathrm{MJ} / \mathrm{kg}$,

- Volume of combustion gas: $280 \mathrm{dm}^{3} / \mathrm{kg}$,

- Combustion gas temperature: $2200^{\circ} \mathrm{C}$.

For cartridges used in tests mass of powder is $0.16 \mathrm{~g}$.

The maximum energy of explosion (assuming that combustion efficiency will be 100-percent):

$$
\mathrm{E}=2800000 * 0.16 / 1000=448 \mathrm{~J} .
$$




\subsection{Detonator made of blasting material}

Primers were shaped in form of cylinders with a diameter of $6 \mathrm{~mm}$ and length from 10 to $20 \mathrm{~mm}$. To firing of primer the electric igniter initiated with voltage of $12 \mathrm{~V}$ was used, controlled via special adapter by computer. Primers were made of $5 \ldots 40 \mathrm{mg}$ of lead azide (usually $15 \mathrm{mg}$ of $\mathrm{Pb}\left(\mathrm{N}_{3}\right)_{2}$ ) or pentryt (PETN up to $700 \mathrm{mg}$ - usually $220 \mathrm{mg}$ ).

Tab. 5. Some properties of the explosives used to make primers

\begin{tabular}{|l|c|c|c|}
\hline & & Lead azide & Pentryt \\
\hline Heat of explosion & $\mathrm{kJ} / \mathrm{kg}$ & 1628 & 1530 \\
\hline Volume of combustion gas & $\mathrm{dm}^{3} / \mathrm{kg}$ & 350 & 768 \\
\hline Temperature of explosion & $K$ & 4373 & 4500 \\
\hline Velocity of detonation wave & $\mathrm{m} / \mathrm{s}$ & 5300 & $3000 \ldots 8300^{*)}$ \\
\hline
\end{tabular}

*) - depends on density: the lower value for $\rho=0.5 \mathrm{~g} / \mathrm{cm}^{3}$, the upper for $\rho=1.73 \mathrm{~g} / \mathrm{cm}^{3}$
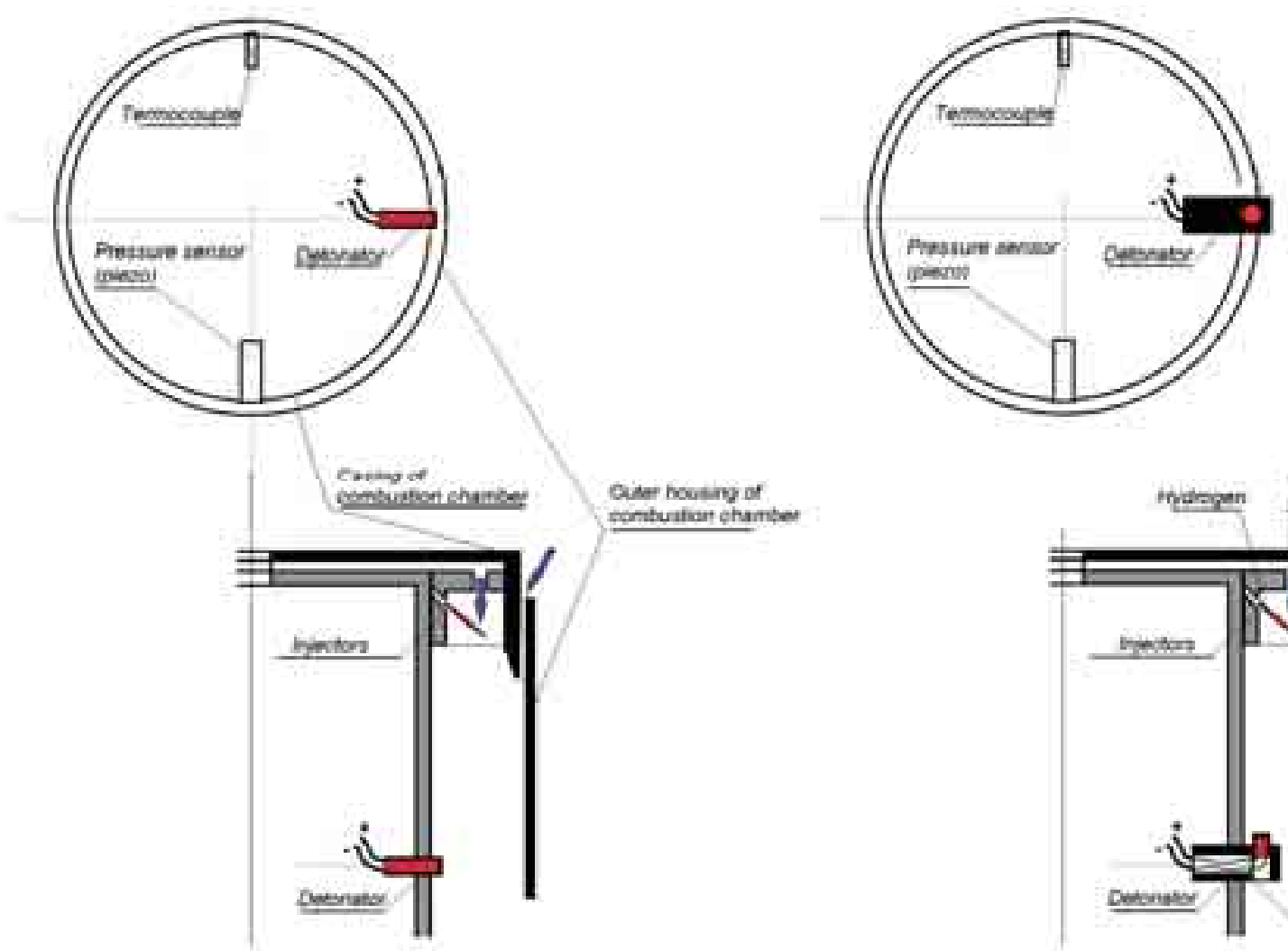

Fig. 8. Arrangement of explosive primers in test stand's combustion chamber

\subsection{Plasma ignition system}

In this case an electric discharge of capacitor charged up to $4500 \mathrm{~V}$ between electrodes within a distance of $7 \mathrm{~mm}$ was used.

Principle of operation: After switching on of HV power supply, capacitor $\mathrm{C}$ is loaded via resistor R to achieve voltage of $4500 \mathrm{~V}$. The voltage is controlled by SHV probe and voltmeter V. Start of firing (discharge) is initiated by switch $\mathrm{S}$. The voltage applied to executive element $\mathrm{Z}$ forces passage of current, which heats copper wire with a diameter of $0.1 \mathrm{~mm}$ and burns it up. This initiates plasma discharge between electrodes. 


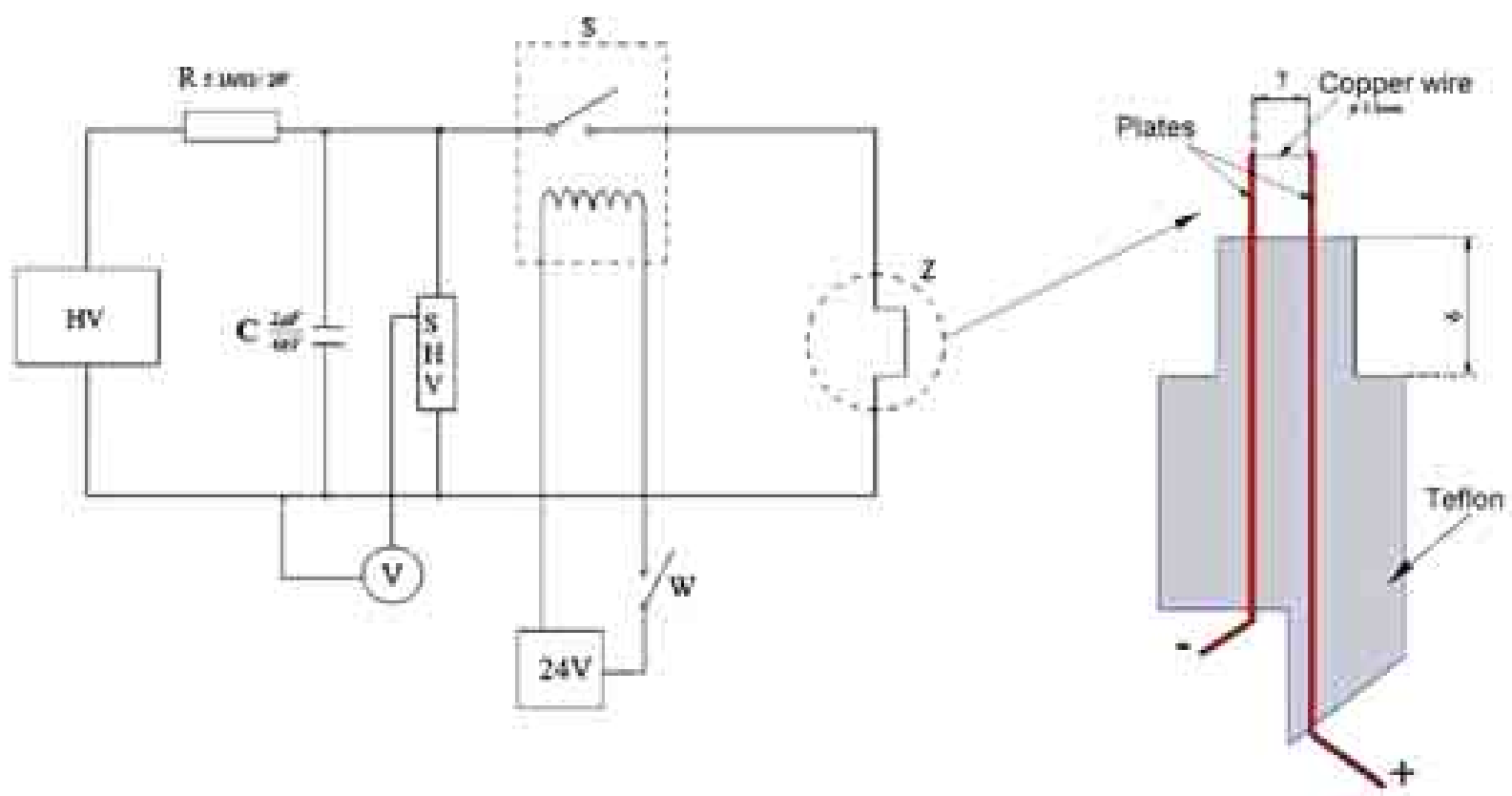

Fig. 9. Diagram of plasma ignition system; Symbols used: HV - high voltage supply ULTRAVOLT $4.5 \mathrm{kV} / 4 m$ A; $S$ - Fast contactor; Z - Wire igniter; SHV - High-voltage probe; V-Voltmeter

Estimation of discharge energy:

$$
\mathbf{E}=\mathbf{C}^{*} \mathbf{U}^{2}
$$

Tab. 6. Estimation of discharge energy

\begin{tabular}{|l|c|c|c|}
\hline & Capacitance & $\begin{array}{c}\text { Voltage on the } \\
\text { capacitor }\end{array}$ & Energy \\
\hline & {$[\mu F]$} & {$[V]$} & {$[J]$} \\
\hline Before discharge & 2 & 4500 & 40.5 \\
\hline After discharge & 2 & 225 & 0.1 \\
\hline Difference: & & & 40.4 \\
\hline
\end{tabular}

The calculated energy of discharge is released at electrodes and in the form of sparks on contactor connectors. The value of this component depends on rate of contactor S.

\section{Test results}

Several tests of detonation were made by changing composition of mixture, type, and location of detonator and - in case of primers - type of explosive material and its mass. Duration of detonation was varied in the range of between 0.5 to 5 seconds. During tests pressures in cylinders containing hydrogen and air in tank decreased, hence their mass flow rate. However, during short trials gradients of these declines were similar, which in effect resulted in almost constant composition of the mixture (lambda) (see Fig. 10 and 11). Flow rates of both components were adjusted by changing the initial pressures in tanks and calculated based on the dynamic pressure (the difference between total and static pressures) and stagnation temperature of medium.

Appearance of detonation was stated by observing the nature of pressure changes in combustion chamber, which were measured by piezoelectric sensors with a frequency of $1 \mathrm{MHz}$. (see Fig.12). Having some experience you can distinguish detonative combustion from deflagration one hearing characteristic sound of high frequency ("whistle") which accompanies the detonation. 


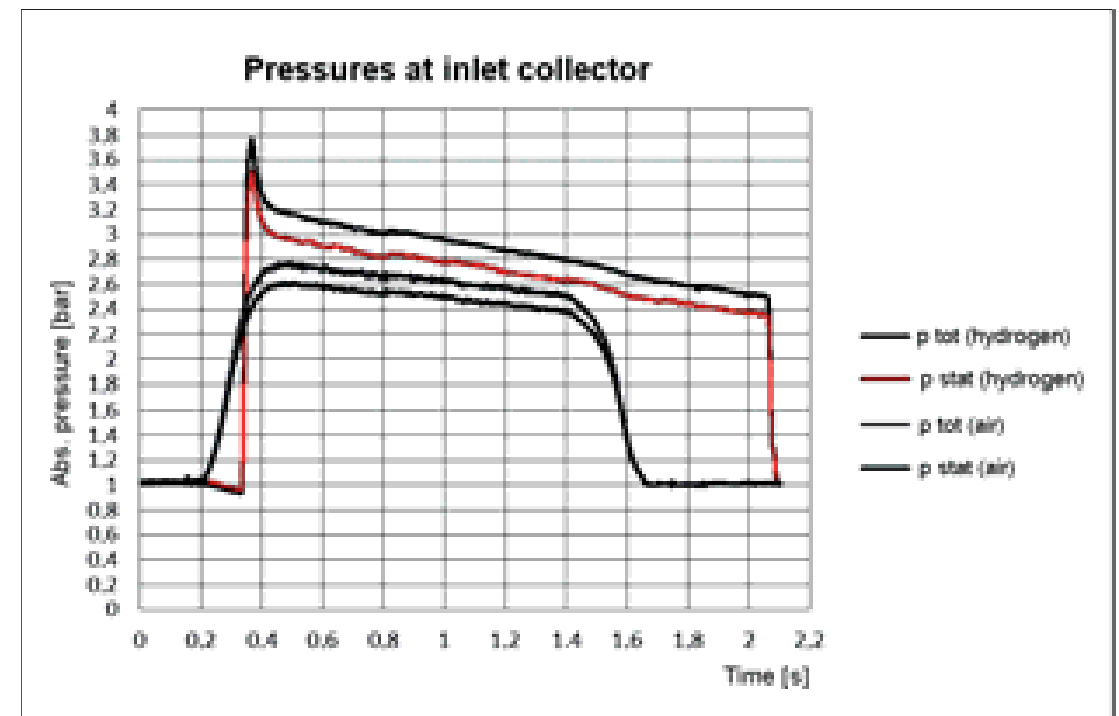

Fig. 10. Changes of static and total pressures of air and hydrogen measured during tests at inlet collectors to injectors

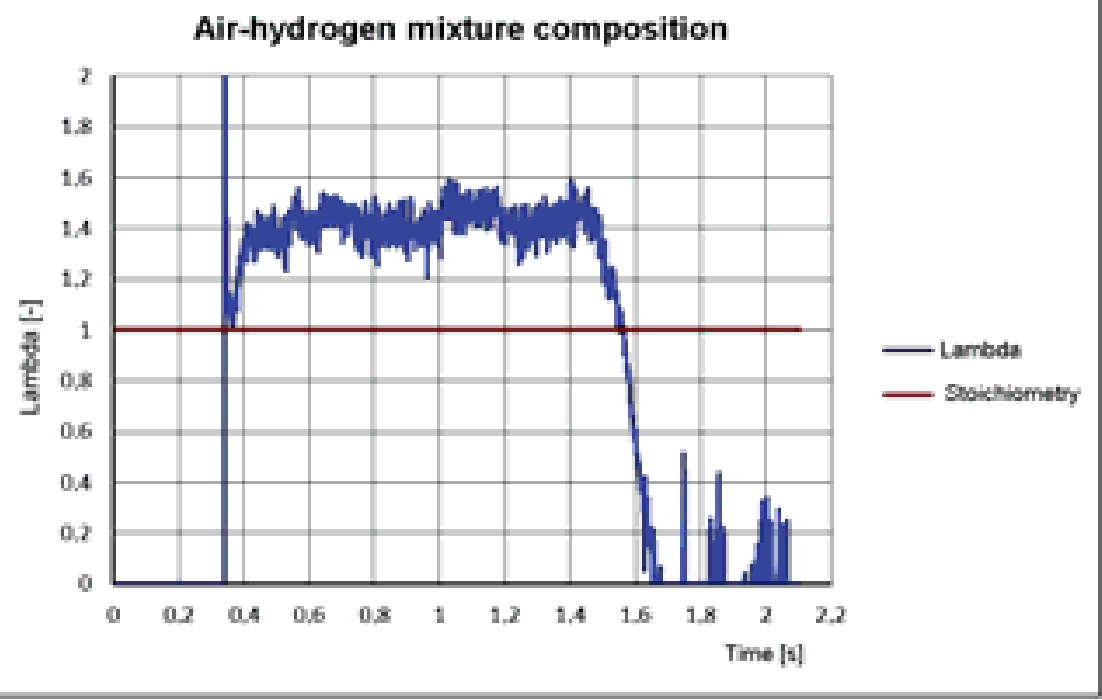

Fig. 11. Changes of air-hydrogen mixture composition calculated based on measured pressures (see Fig.10)

\section{Analysis of the results}

Tests of detonative combustion of air / hydrogen mixtures allow formulating a few observations:

1. Detonative combustion occurs when:

- fuel is thoroughly mixed with air - placing an initiator too close to injectors which feed the chamber separately with fuel and air makes it difficult to initiate detonative combustion,

- initialization system produces a sufficiently high energy - it is preferred that the process should be stretched in time. Even a fairly high energy delivered in form of peak does not guarantee initiation of detonative combustion);

Composition of mixture is not too lean $(\lambda$ ratio $<2.5)$.

2. Effectiveness of proven initiator systems is different:

- the most effective systems seem to be those generating a gas stream of high energy, such as powder cartridge (or detonation tube filled with a mixture of acetylene and oxygen, used in test conducted at IHE WUT), 

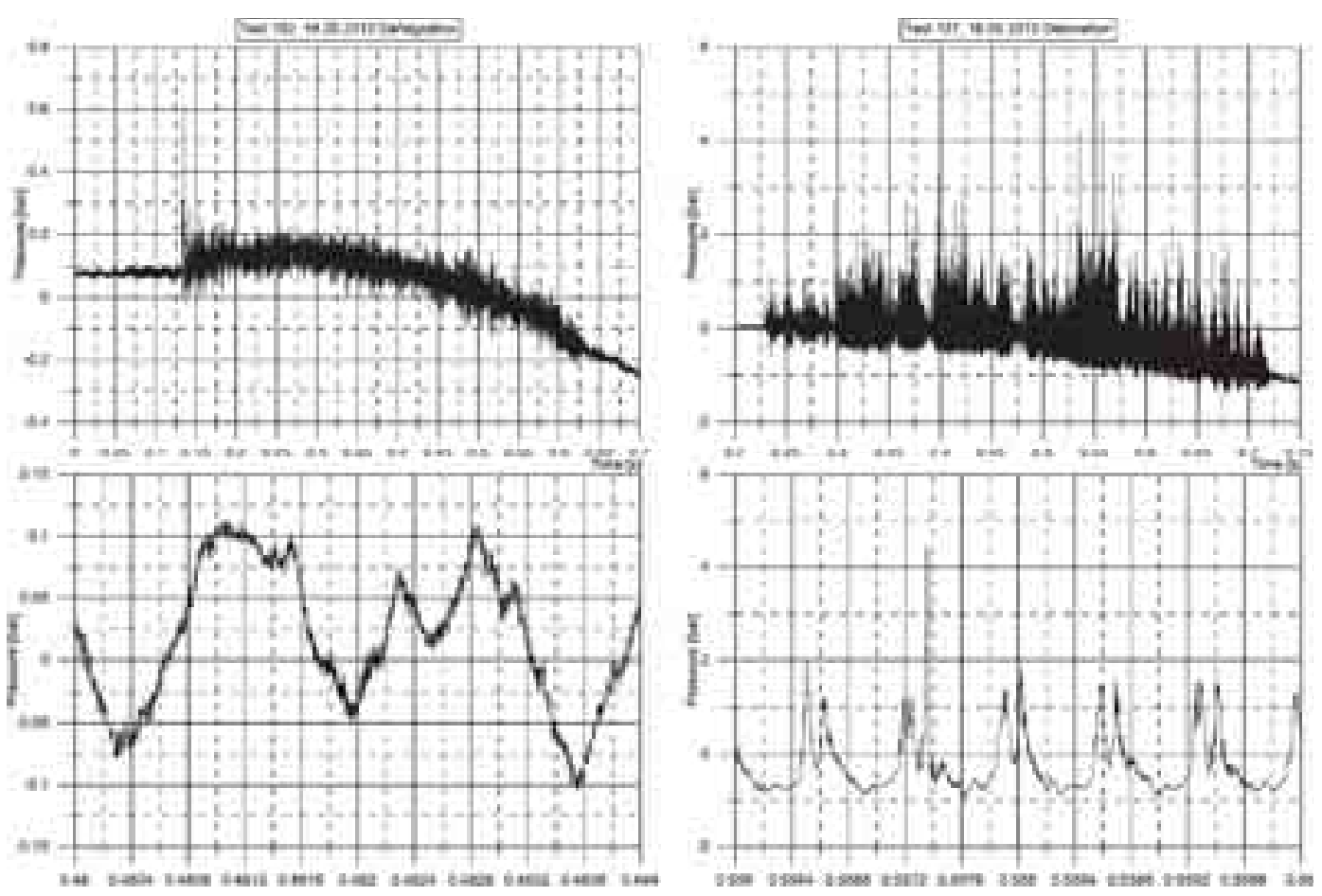

Fig. 12. Course of changes in combustion gas pressure - signals from Kistler piezoelectric sensor (sampling frequency of $1 \mathrm{MHz}$ ) for deflagration (left) and detonation (right) combustion

- High voltage system for plasma ignition was also characterized by high efficiency. Its disadvantage may be a risk of electric shock caused by high voltage of about $4 \mathrm{kV}$,

- Pyrotechnic detonators were quite effective, but should be placed inside the combustion chamber (their effectiveness is highly dependent on their placement and making use of these is very dangerous),

- Ignition using turbine engine spark plugs was not effective - its energy was too low to initiate a detonation.

\section{References}

[1] Baker, W. E, Tang, M. J., Gas, Dust and Hybrid Explosions, Fundamental Studies in Engineering 13, 1991.

[2] Bykovski, F. A., Verdernikov, E. F, Polozov, S. V., Golubev, Yu. V, Initiation of Detonation in Flows of Fuel-Air Mixtures, Combustion, Explosion and Shock Waves, Vol. 43, No. 3, 2007.

[3] Dzierżanowski, P. et al., Turbinowe silniki odrzutowe, Wyd. Kom. i Łączności, Warszawa 1983.

[4] Kindracki, J., Badania eksperymentalne i symulacje numeryczne procesu inicjacji wirujacej detonacji gazowej, rozprawa doktorska, prom. prof. Piotr Wolański, Wydział MEiL, Politechnika Warszawska, 2008.

[5] Kindracki, J., Wolański, P., Badania laboratoryjne wirującej detonacji $w$ aspekcie zastosowań do silnika odrzutowego, Polskie Towarzystwo Astronautyczne Postępy Astronautyki, T. 29, Nr 1, 2006.

[6] Kuo, K., Principles of combustion, Wiley, New York 1986.

[7] Lee, J. H., Matsui, H., A comparison of the critical energies for direct initiation of spherical detonations in acetylene-oxygen mixtures, Combustion and Flame, 28, 1977.

[8] Sobey, A. J., Suggs, A. M., Control of aircraft and missile powerplants, Wydawnictwo John Wiley\&Sons, New York, London 1963.

[9] Schroeder, V., Holtappels, K., Explosion Characteristics of Hydrogen-Air and HydrogenOxygen Mixtures at Elevated Pressures, Research Center Jülich, Germany, European research project SAFEKINEX, 2003..2007. 